\title{
Study on shaping slope stability of dump in eastern grassland open-pit mine
}

\author{
Guo Xiaoli ${ }^{1,4}$, Yan Jiancheng ${ }^{2,3,6^{*}}$, Li Xueliang $^{5}$, Wen Xin ${ }^{1,4}$, Li Xingli $^{6}$ \\ ${ }^{1}$ CCTEG Beijing Research Institute of Land Renovation and Ecological Restoration Technology Co.,Ltd., Beijing, 100013, China \\ ${ }^{2}$ Tiandi(Tangshan) Mining Technology Co.,Ltd., Tangshan 063300,China \\ ${ }^{3}$ Tangshan Research Institute, China Coal Technology \& Engineering Group, Tangshan, 063012, China \\ ${ }^{4}$ Research centre of land Renovation and ecological restoration engineering in the coal industry, Beijing, 100013, China \\ ${ }^{5}$ China Coal Science and Technology Ecological Environment Technology Co.,Ltd., Beijing 100013,China; \\ ${ }^{6}$ Tangshan Branch of China Coal Science and Technology Ecological Environment Technology Co.,Ltd.,Tangshan, 063012, China
}

\begin{abstract}
The dumps in the open-pit mining area in the eastern grassland are prone to landslides due to the fragile ecological environment, so it is inevitable to reshape the dump slopes. In order to explore a more scientific method for slope shaping of open-pit mine dump, slope stability analysis were used to compare effect of three types of slope-type (wave-shaped, slope-shaped and step-shaped slope shaping method)in outside dumping site of Baori Hiller open-pit mine. The results show that the slope stability is negatively correlated with the slope angle, and the stability of different shaping slopes is realized as wave-shaped slope $(F=2.711)>$ Slope-shaped $\operatorname{slope}(F=2.513)>\operatorname{Step}$-shaped slope $(F=1.047)$, in which the wave type and slope type are all within the safe range, but the step type slope is unstable; in consideration of cost, stability and erosion resistance, it is better to set the slope angle of the dump to $15^{\circ}$. The wave-shaped shaping method of the natural dumping of the excavation field outside the Baori Hiller open-pit mine has the best effect and is worth promoting.
\end{abstract}

\section{Introduction}

The eastern grassland area is an important coal base in China, with simple mining conditions and low mining costs. However, due to the fragile ecological environment, open-pit mining severely damages the ecology and causes various environmental problems. The sustainable and stable development of mine is directly related to the stability of mining slope and dump slope ${ }^{[1]}$. Dump slope is a tower-like multi-step slope mainly composed of loose deposits. In addition to surface erosion and gully erosion, there are also new erosion types such as subsidence, collapse and slope debris flow, which are the most unstable and serious soil and water loss places. The slope stability of dump affects the production safety of the openpit mine, and treatment difficulty of outside dump slope is far greater than that of flat panel ${ }^{[2]}$.

At present, the research on the slopes of outside dump focuses on different vegetation configuration modes ${ }^{[3-4]}$, erosion degree and erosion control methods ${ }^{[5-6]}$, and soil physical and chemical properties ${ }^{[7-8]}$, but there is little research on slope shaping methods. Some scholars pointed out that the design of imitating the natural landform can make the reconstructed and reconstructed land landscape more harmonious and stable, and the ecological structure more reasonable $e^{[9]}$.

Thus, this paper takes the outside dump of Baori Hiller open-pit mine as the research object, designs three different shaping methods based on the topography and geomorphology characteristics of mining loss area and the surrounding mature areas. Evaluate the effect of slope remediation by analyzing slope stability, and screen out the most suitable reshaping method.

\section{Materials and methods}

\subsection{Study area}

This study area is located in Hulunbeier City, Inner Mongolia Autonomous Region(Fig.1). With geographical coordinates are $119.9836^{\circ}$ to $119.9686^{\circ} \mathrm{E}, 49.3125^{\circ}$ to $49.4917^{\circ} \mathrm{N}$. The climate was continental sub cold zone climate, with abundant spring and winter monsoons and strong winds. The average annual precipitation is from $190 \mathrm{~mm}$ to $406 \mathrm{~mm}$, with more than $70 \%$ of the annual precipitation occurring in June, July and Augus , and annual average evaporation is $1344.80 \mathrm{~mm}$, annual average temperature is $-2.6^{\circ} \mathrm{C}$. the terrain is higher in the northeast and lower in the southwest, with an altitude of $601.88 \sim 724.09 \mathrm{~m}$, most of the surface layer is covered by quaternary system. The soil type in study area were dominated by chernozem, chestnut soil and gray-black soil. The wild vegetation is dominated by gramineae and compositae, artificially planted tree were Pinus sylvestris var, Pinus tabulaeformis, and shrubs are Sorbaria sorbifolia Syringa oblata Lindley.

\footnotetext{
*Corresponding author:jc_yan@163.com
} 
The poor stability of the open-pit slope is mainly soft rock, which is easily affected by weak mudstone layers and groundwater; the waste material of the dump is mainly the Quaternary loose rock group, which is divided into sandstone, clay rock and glutenite, and stacking method is to compact the waste. The reclamation period in this area is 2 years due to the surface of the new steps formed by accumulation has not been covered with soil.

\subsection{Research methods and analysis}

The earliest and the most well-developed method in slope stability analysis is limit equilibrium analysis, which can satisfy the equilibrium of force and moment, MohrCoulomb failure criterion and stress boundary conditions. Zhang ${ }^{[10]}$ proposed that circular sliding and combined sliding analysis can be used for the dump by summarized the stability analysis methods and specific ideas of soilrock composite slope, for the lower rock mass (stope), the dangerous surface is determined according to the combination of structural surfaces, and the residual reasoning method is generally used for analysis.

Slope safety stability factor $(F)$ means that reducing the shear strength of the rock and soil mass to $c^{\prime} / F$ and $\tan \varphi^{\prime} / F$, and the mass will bi in limit equilibrium along the sliding surface ${ }^{[11]}$, it can be expressed as:

$$
\tau=c_{\mathrm{e}}^{\prime}+\sigma_{\mathrm{n}}^{\prime} \cdot \tan \phi_{\mathrm{e}}^{\prime}
$$

Where, $\tan \varphi_{e}^{\prime}=\tan \varphi^{\prime} / F, \quad c_{e}^{\prime}=c^{\prime} / F, \quad F$ is the stability safety factor, $c^{\prime}$ is the cohesion, $\varphi^{\prime}$ is the internal friction force, $\tau$ is the shear stress, $\sigma_{n}^{\prime}$ is the normal stress.

Mohr-Coulomb failure criterion. Its premise is to assume that a certain section of rock and soil slides along a certain sliding surface. This segment reaches equilibrium all points on the slip surface, that is, $\sigma_{n}^{\prime}$ and $\tau$ conform to the Moore-Coulomb criterion. Suppose the normal stress and tangential stress at the bottom of a block are $N$ and $T$ respectively, then:

$\triangle T=c_{e}^{\prime} \Delta x \sec \alpha+(\Delta N-u \triangle x \sec \alpha) \tan \phi_{e}^{\prime}(2)$

Where, tan $\alpha$ is bar bottom inclination, and value is $d y / d x ; u$ is pore water pressure, pore water pressure coefficient $r_{u}=u /(d W / d x)$

Equilibrium condition. For the divided blocks, the balance of forces and moments should be satisfied between the blocks and the whole rock and soil mass.

In this study, the simplified Bishop method ${ }^{[12]}$ was used to calculate the stability of three types of reshaped slope based on the engineering geological conditions of the outside dump slope. In Bishop method, the slope body is divided into several blocks, in which the slice is assumed to be a rigid body (without considering the deformation of the strip), the static equilibrium equation of the slice is established, and the slope safety factor is obtained by solving the static equilibrium equation.

The data of the slope material comes from relevant engineering geological reports and documents, and the stability analysis of the slope is carried out in the Slide software。

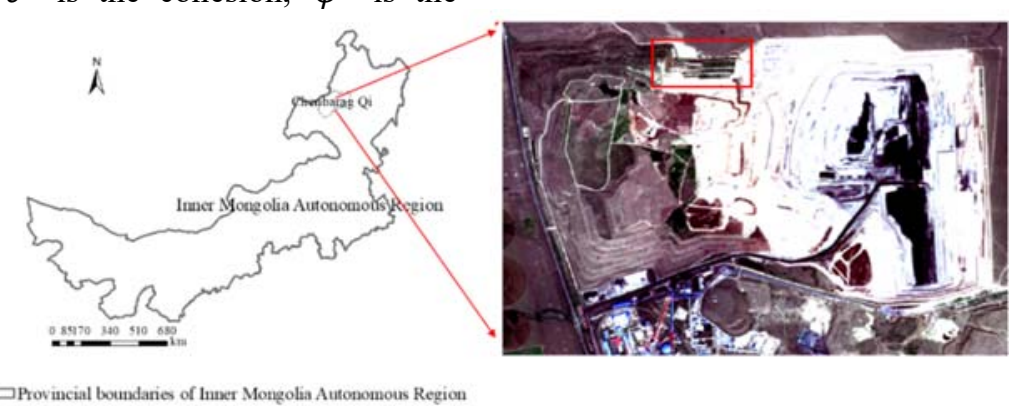

Fig.1 Location of study area

\section{RESULTS}

\subsection{Slope shaping of dump based on natural landform}

The rainfall in the study area is mainly concentrated in summer. In order to prevent continuous rainfall from scouring the slope surface of the dump scouring the slope surface of the dump and ensure water for vegetation growth, the method of step-shaped, slope-shaped and wave-shaped were designed with reference to the surrounding natural landforms(Fig.2).

The step-shaped slope is to optimize the three platforms of $670 \mathrm{~m}, 660 \mathrm{~m}$, and $650 \mathrm{~m}$ designed for the original dumping, which is the comparison of the other two shaping methods. Specifically, a retaining wall was built on the top of the $680 \mathrm{~m}$ platform, with a width of 2 $\mathrm{m}$ and a height of $1 \mathrm{~m}$, the design parameters of natural grading are that the platform width is $50 \mathrm{~m}$, the step height is $15 \mathrm{~m}$, and the slope angle is $33^{\circ}$.

The slope-shaped slope is to cut the slope of the dumping platform under the premise of considering the conditions of the dumping site and the slope angle trend, so that the original $33^{\circ}$ slope angle is reduced to $11 \pm 0.5^{\circ}$.and an east-west direction 4 slopes with a total length of $200 \mathrm{~m}$.

The wave-shaped slope is based on the surrounding natural topography and landforms, the original $33^{\circ}$ slope of the dumping platform is cut, and a anti-slope area is built at the edge of the platform with a slope of $3 \sim 5^{\circ}$ to control soil erosion. The $50 \mathrm{~m}$ platform is cancelled, the height of the steps remains unchanged, and finally form a slope angle of $15 \pm 0.5^{\circ}$ similar to the surrounding topography.

A wide shallow dry masonry area is designed at the bottom of the flat plate of each shaping slope, with a width of $6 \mathrm{~m}$ and a depth of $0.8 \mathrm{~m}$, with $0.3 \mathrm{~m}$ of gravel on top. 
Finally, plant elymus dahuricus on the platform and slope at a planting rate of $40 \mathrm{~g} / \mathrm{m}^{2}$.

\subsection{Stability analysis of different shaped slopes}

The main factors affecting the stability of the dump slope include geological conditions of the basement, climatic condition, dumping technology, and physical properties of the dumped material. The strength of dumped materials is the main parameter of slope stability analysis and calculation, which directly affects the slope stability. The profile configuration of dump and the physical and mechanical parameters of the rock and soil are determined based on the engineering geological data of the Baori Hiller open-pit mine. The profile configuration is
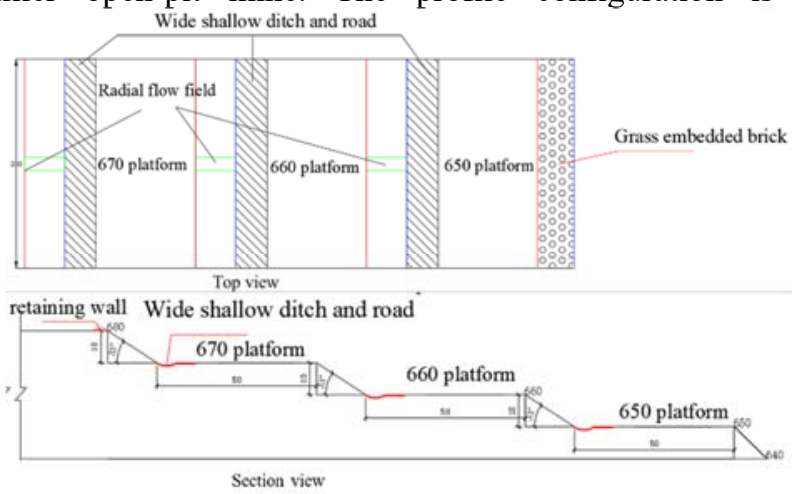

Step-shaped slope dumping material layer-silt layer-clay layer, and the bulk density of the dump is $16.86 \mathrm{kN} / \mathrm{m}^{3}$, the internal friction angle is $25.5^{\circ}$, and the cohesion is $2.98 \mathrm{kPa}$; bulk density of the silt is $18.42 \mathrm{kN} / \mathrm{m}^{3}$, the internal friction angle is $26^{\circ}$, and the cohesion is $6.78 \mathrm{kPa}$; the bulk density of the clay is $18.42 \mathrm{kN} / \mathrm{m}^{3}$, the internal friction angle is $20^{\circ}$, and the cohesion is $6.98 \mathrm{kPa}$. The potential sliding mode of the slope in the dump is circular arc sliding, the simplified Bishop method was used to analyze the stability of the three reshaped slopes of the dump on the Slide software, and the influence law of the slope angle on the stability of the slope was revealed to determine the optimal shape of the slope.

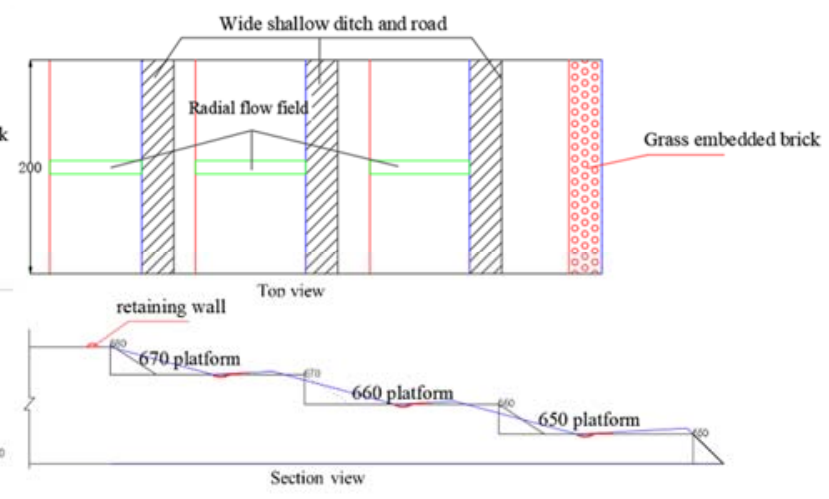

Wave-shaped slope

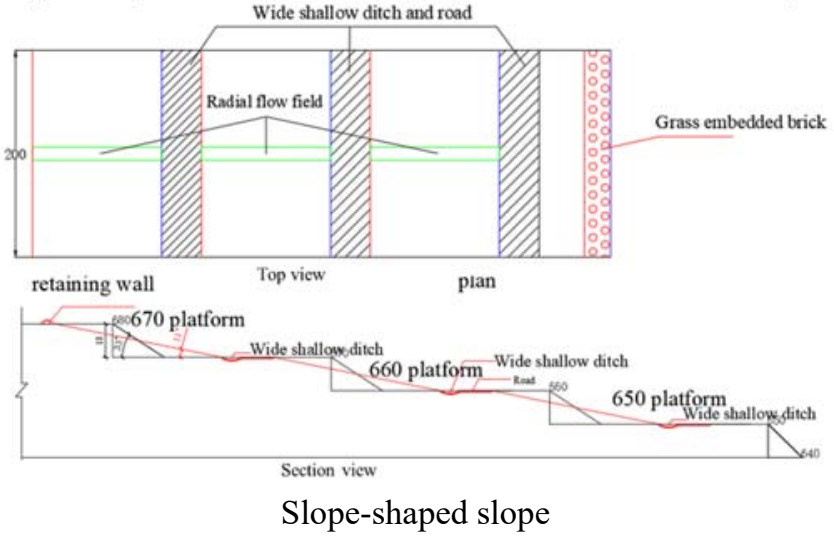

Fig.2 Plane and Section of Different Slope Shaping

The stability analysis of three kinds of shaping slopes is shown in Fig.3. The safety factor of the dump slope is negatively related to the slope angle, the smaller the slope angle, the more stable the slope and the less likely to occur landslides. From the perspective of stability factor, the wave-shaped slope is larger than the slope-shaped than the step-shaped. According to the "GB50197-2015 Code for design of open pit mine of coal industry", the safety factor of the external dumping slope with a service life of more than 20 years is between 1.2 and 1.5 and division of landslide stability state in "DZ/T0218-2006 Specification of geological investigation fog landslide stabilization", safety factor $(F=1.073)$ of the step-shaped slope is lower than 1.2, and the slope landslide is in an overall temporarily stable-deformed state. The slope-shaped and wave-shaped slopes are in a stable state, of which the safety factor of wave type slope is the highest $(F=2.711)$, followed by slope type $(F=2.513)$. Three shaping slopes are adjacent to each other and their dump is consistent with geological condition. Therefore, the slope angle plays a key role in the stability of the slope of outside dump the Baori Hiller open-pit mine.

\section{Discussion}

On the one hand, the dumping is under the action of the weight stress of the dumped materials, and the dumped soil is compacted to produce settlement deformation; on the other hand, due to the excessive self-weight stress, the bearing capacity of the base is insufficient, and the soft 
layer of the base is squeezed and sheared, which is easy to produce plastic flow and cause landslide of the dump ${ }^{[13]}$.

Due to long slope and loose slope of the dumping, the soil water holding capacity is insufficient, and the plant growth is difficult, which is prone to soil erosion. Analysis of the stability of three reshaped slopes found
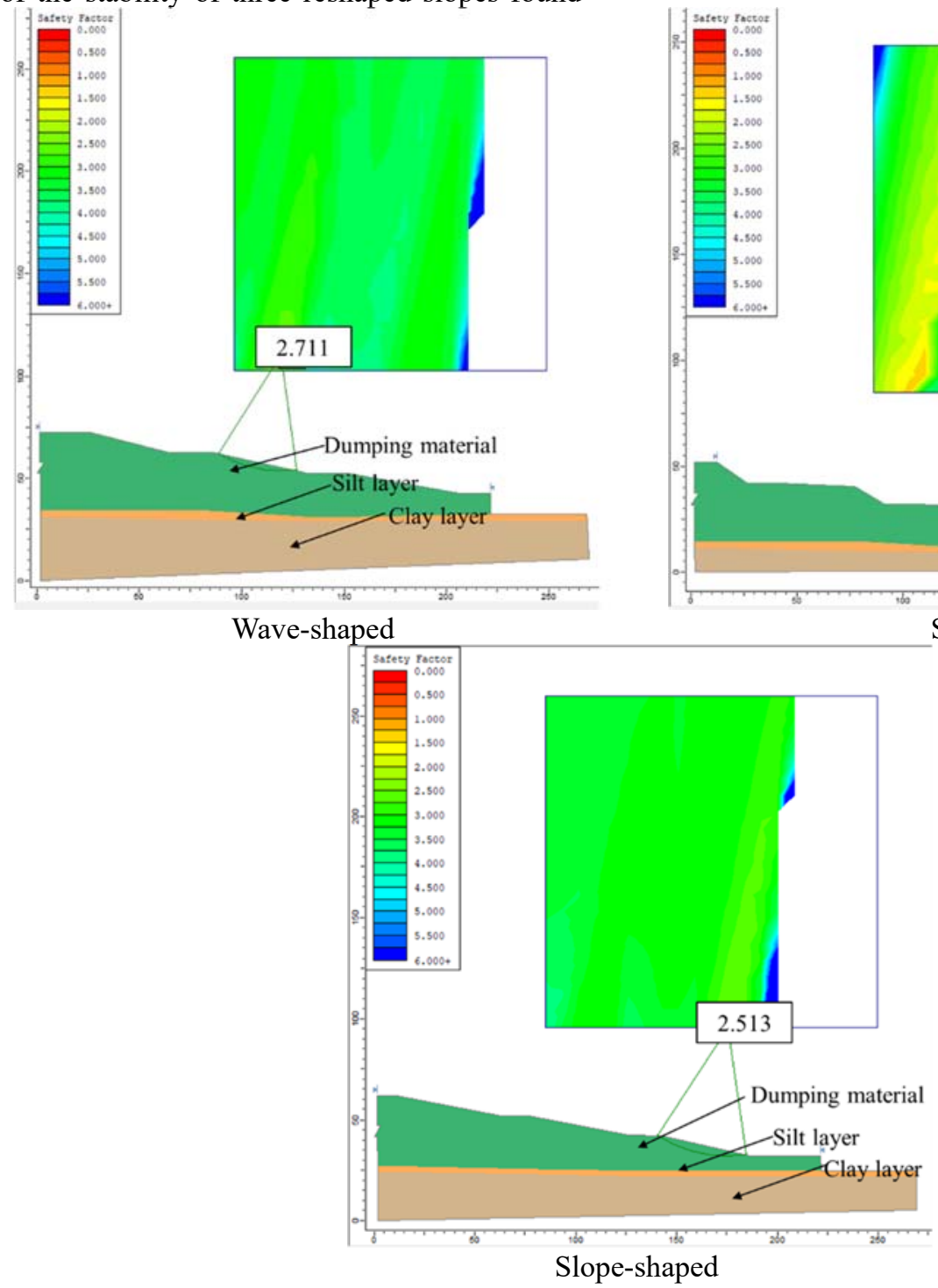

Fig.3 Stability Analysis of Different Shaping Slopes that the slope angle affects the stability of the slope. The safety factor of the slope-shaped slope and the waveshaped slope are improved after slope cutting treatment. Generally, the smaller the slope angle, the more stable the slope is, slope angle of the sloping slope is smaller than

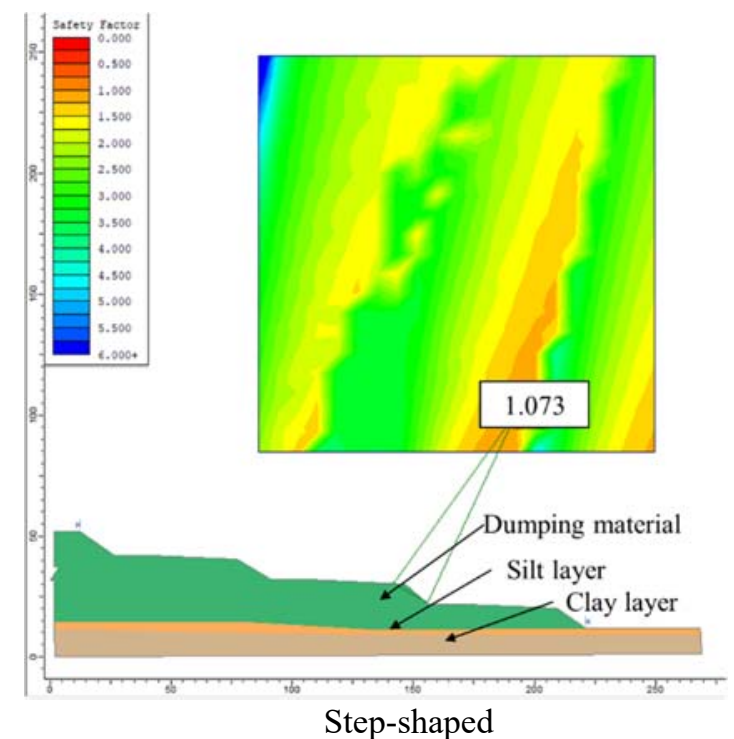

Step-shaped that of the wave slope, but the safety factor of the sloping slope is greater than that of the sloping slope, which are within the stable range. This may be due to the improvement of soil and water conservation performance, good vegetation growth and slope stability after the construction of reverse slope area. By comparing the research of domestic and foreign scholars ${ }^{[2,14-15]}$ found that the slope shaping of the outside dump is mostly between $11^{\circ}$ and $24^{\circ}$.In this study, the slope-shaped and wave-shaped slope angle set by the principle of imitating natural landforms and the actual conditions of the Baori Hiller open-pit mine, and the wave shaping method is the most suitable shaping method.
Through the analysis of slope stability, both slope-shaped slope and wave-shaped slope are in a stable state, among which the wave-shaped slope is the most stable, and the stepped-shaped slope landslide is basically in a stable state. The wave-shaped method based on water and soil conservation to imitate natural landforms is a landscape and ecological restoration technology with low investment, low maintenance, and high ecological benefits for the shaping of outside dump of Baori Hiller Open-pit Mine. At the same time, vegetation type should also be optimized. Agropyron cristatum(L) and Medicago sativa(L) can adapt well to the climatic conditions in the Hulunbuir region and are the main species that construct the basic framework of the ecosystem.

\section{Conclusion}




\section{Acknowledgements}

This research was supported by the Science and Technology Innovation and Entrepreneurship Fund Special Youth Project of Tiandi Technology Co., Ltd (2018-TD-QN041), National Key Research and Development Program of China (2016YFC0501105) and High level talents funding project in Hebei Province (A202001096). The authors are deeply grateful to anonymous reviewers and the editor for their helpful comments on the manuscript.

\section{References}

1. GUAN Xiaoming,WANG Xuchun,NIE Qingke,et al. Stability. Analysis and parameters optimization of an open-pit slope[J]. Safety in Coal Mines,2018,49(5):71-74.

2. HAN L,SHU J,CAI Q,et al. Mechanical characteristics of dip basement effects on dump stability in the Shengli open pit mine in Inner Mongolia, China [ J]. Arabian Journal of Geosciences,2016, 9(20):750.

3. SHAN Dan,XING Ende,RONG Hao,et al. Ecological restorationof different vegetation collocations of coal mine dump in typicalsteppe[J]. Chinese Journal of Ecology,2019,38(2):336-342.

4. QI Xue. Ecological restoration measures applications primary evaluation in Xinlin Gol Grassland Mine Dump[D]. Hohhot: Neimenggu Agriculture University,2017.

5. YANG Bo. The erosion reduction effect and mechanism of different vegetation allocation patterns on the slope of mine dump[D]. Xianyang:Northwest A \& F University,2019.

6. LIU Yanping,LIANG Zhanqi,HE Jingli,et al. Study on water saving irrigation measures for vegetation restoration in mining area of mining area[J]. Grassland and Lawn,2018,38(5):16-21.

7. SUN Mengyuan,LIU Jinghui,MI Junzhen,et al. Effects of vegetation reclamation on soil chemical and biological characteristics of dumping sites in open-pit coal mines[J]. Journal of Soil and Water Conservation,2019,4:206-212.

8. LIU Jun,DING Xia,ZHANG Wuwen. Study on soil fertility of artificial sea-buckthorn woodlands in the waste dump of Huolinhe south-pit mine [ J]. Resources and Environment in Arid Area,2017, 31(12):150-154.

9. ALAN B. Designing the reclaimed landscape[M]. London \& New York:Taylor and Francis, 2008.

10. ZHANG Lianhua, TANG Lingxiang, LUO kang. A method for stability anal ysis and calculation of soilrock mixed slope [J]. Geotechnical Engineering Technology, 2008 (03): 119-122.

11. Yao yong.Slope stability analysis based on threedimensional engineering geological model[D].Liaoning Technical university, 2009.

12. ZHU Dayong, DENG Jianhui, TAI Jiajia. Demonstration of the Strictness of the Simplified Bishop Method [J]. Journal of Rock Mechanics and Engineering, 2007 (03): 455-458.

13. ZHAO Ruixi,YU Yantao,ZHU Xinping. Slope stability analysisof dump in Harusu open-pit mine[J]. Opencast Mining Technology,2009(5):26-27.

14. ZHENG Haolin,FENG Shurong. Study on the renovation and expansion design of Weishan Liangzi dump [ J]. World NonferrousMetals,2019(10):194196.

15. LI Guanghua, GAO Yongxing. Research on ecological environment restoration and control technology of dump in Huolinhe mining area [J]. Environment and development, 2019, 31 (06): 176177 